\title{
A Cross-sectional Study on Interference Control: Age Affects Reactive Control but not Proactive Control
}

\author{
Yanfang Peng ${ }^{1,2}$, Qin Zhu ${ }^{3}$, Biye Wang ${ }^{4}$, Jie Ren ${ }^{\text {Corresp. } 5}$ \\ ${ }^{1}$ School of Physical Education and Coaching, Shanghai University of Sport, Shanghai, Shanghai, China \\ 2 Division of Sport Science, Wenzhou Medical University, Wenzhou, Zhejiang, China \\ 3 Division of Kinesiology and Health, University of Wyoming, Laramie, WY, US \\ 4 Division of Sport Science, Yangzhou University, Yangzhou, Jiangsu, China \\ ${ }^{5}$ China Table Tennis College, Shanghai University of Sport, Shanghai, Shanghai, China \\ Corresponding Author: Jie Ren \\ Email address: renjie@sus.edu.cn
}

Background. Working memory updating (WMU), a controlled process to continuously adapt to the changing task demand and environment, is crucial for cognitive executive function. Although previous studies have shown that the elderly were more susceptible to cognitive interference than the youngsters, the picture of age-related deterioration of WMU is incomplete due to lack of study on people at their middle ages. Thus, the present study investigated the impact of age on the WMU among adults by a cross-sectional design to verify whether inefficiency interference control accounts for the aging of WMU. Methods. In total, 112 healthy adults were recruited for this study; 28 old adults (21 female) ranging from60-78 years of age; 28 middle-age adults ( 25 female) ranging from 45-59 years of age; 28 adults ( 11 female) ranging from 26-44 years of age; and 28 young adults ( 26 female) ranging from 18-25 years of age. Each participant completed a 1-back task. The inverse efficiency score (IES) was calculated in various sequences of 3 trials in a row to quantify the performance of WMU for adults of various ages. Results. Inverse efficiency score (IES) of both young groups (young adult and adult) were significantly shorter than the old group in both Repeat-Alternate (RA, including $\square \square \bigcirc$ and $\bigcirc \circ \square$ ) and Alternate-Alternate (AA, including $\bigcirc \square \bigcirc$ and $\square \bigcirc \square$ ) sequential patterns and they were additionally better than the middle-age group in AA sequential pattern . Conclusion. With the increase of difficulty in the task, the difference in reactive interference control between young and middle age was gradually revealed, while the difference between young and old remained to apparent. The degradation of WMU aging may begin from middle-age and presents selective impairment in that only reactive interference control, but not proactive interference control, shows pronounced age-related decline. The preliminary results can inform future studies to further explore the whole lifespan trajectories of cognitive 
functions. 
1 A Cross-sectional Study on Interference Control: Age Affects

2 Reactive Control but not Proactive Control

4 Yanfang Peng ${ }^{1,2}$, Qin $\mathrm{Zhu}^{3}$, Biye Wang ${ }^{4}$, Jie Ren $^{5}$

$5 \quad{ }^{1}$ School of Physical Education and Coaching, Shanghai University of Sport, Shanghai, China

$6 \quad{ }^{2}$ Division of Sport Science, Wenzhou Medical University, Wenzhou, Zhejiang, China

$7 \quad{ }^{3}$ Division of Kinesiology and Health, University of Wyoming, Laramie, WY, United States of America

$8{ }^{4}$ Division of Sport Science, Yangzhou University, Yangzhou, Jiangsu, China

$9{ }^{5}$ China Table Tennis College, Shanghai University of Sport, Shanghai, China

11 Corresponding Author:

12 Jie Ren

13399 Chang Hai Road, Shanghai, 200438, P. R. China

14 Email address: renjie@sus.edu.cn

Abstract

Background. Working memory updating (WMU), a controlled process to continuously adapt to changing task demands and environment, is crucial for cognitive executive function. Although previous studies have shown that the elderly were more susceptible to cognitive interference than the youngsters, the picture of age-related deterioration of WMU is incomplete due to a lack of study on people at their middle ages. Thus, the present study investigated the impact of age on the WMU among adults by a cross-sectional design to verify whether inefficiency interference control accounts for the aging of WMU.

Methods. In total, 112 healthy adults were recruited for this study; 28 old adults (21 female) ranging from 60-78 years of age; 28 middle-age adults (25 female) ranging from 45-59 years of age; 28 adults (11 female) ranging from 26-44 years of age; and 28 young adults (26 female) 
ranging from 18-25 years of age. Each participant completed a 1-back task. Inverse efficiency score (IES) was calculated in various sequences of 3 trials in a row to quantify the performance of WMU for adults of various ages.

Results. Inverse efficiency score (IES) of both young groups (young adult and adult) were significantly shorter than the old group in both Repeat-Alternate (RA, including $\square \square \bigcirc$ and $\bigcirc$ $\bigcirc \square$ ) and Alternate-Alternate (AA, including $\bigcirc \square \bigcirc$ and $\square \bigcirc \square$ ) sequential patterns and they were additionally better than the middle-age group in AA sequential pattern.

Conclusion. With the increase of difficulty in the task, the difference in reactive interference control between young and middle age was gradually revealed, while the difference between young and old remained to be apparent. The degradation of WMU aging may begin from middleage and presents selective impairment in that only reactive interference control, but not proactive interference control shows pronounced age-related decline. The preliminary results can inform future studies to further explore the whole lifespan trajectories of cognitive functions.

\section{Introduction}

Cognitive aging has been a central theme (Anderson \& Craik, 2017) of the growing global aging because the compromised cognitive functioning in later life is a risk factor for increased morbidity and mortality (Bruce, Hoff, Jacobs, \& Leaf, 1995). Effective cognitive function can help old adults to maintain independence and promote quality of life in old age (Royall, Palmer, Chiodo, \& Polk, 2005). The purpose of exploring age-related cognitive changes is to discover an aging mechanism and to provide preventative interventions. In the past two decades, a substantial body of research has documented the decline of cognition for old adults compared to young adults. The progression of aging is unclear because middle age has been understudied, however, investigating this period of the lifespan is important for the understanding of 
51

52

53

54

55

56

57

58

senescence.

Since WM is capacity-limited, working memory updating (WMU) is used to continuously adapt to changing task demands and environment (Morris \& Jones, 1990), and is crucial for cognitive executive function. Updating is a process of dismantling and recreating associations between content and context (Artuso \& Palladino, 2018). That is, unbinding the outdated contents from their contexts in time and establishing new bindings (Oberauer, 2009). It is hard to distinguish between outdated and new items particularly when they're similar. Many studies have proved that the WMU of young adults over older adults was better, because older adults decreased the ability to modulate brain activation and they could not maintain a better availability of attention representations to efficiently inhibit irrelevant information (Arjona, Escudero, \& Gómez, 2016; Fiore, Borella, Mammarella, \& Cornoldi, 2011; Podell et al., 2012; Sambataro et al., 2015). Old adults need larger accuracy cost and an additional focus-switch cost, which is the cost of switching attention to relevant information (Schmiedek, Li, \& Lindenberger, 2009; Verhaeghen \& Basak, 2005), especially old-old adults (Borella, Carretti, Cornoldi, \& De Beni, 2007; De Beni \& Palladino, 2004; Kato et al., 2016). The inefficient inhibition of irrelevant information was thought to be the crucial reason for WMU aging. But Borella, Carretti, and De Beni (2008) recruited 304 subjects age-range 20-86 to measure 4 kinds of WM tasks and 2 kinds of inhibition tasks. Results showed that inhibition was not as a crucial contributor to age-related decline in the functional capacity of WM across the adult life-span as previously thought. Recently, Dagry, Vergauwe, and Barrouillet (2017) suggested that during WMU, attention was allocated to capture current goals but not to inhibit stimulus that should be ignored. 

2012). When the task contains high interference, the task will tax more cognitive control resources to protect the contents of memory against interference (Szmalec, Verbruggen, Vandierendonck, \& Kemps, 2011). Control processes in WMU are responsible for selecting relevant information; preventing interference; updating at appropriate junctures and so on (Braver et al., 2012). Kessler and Meiran (2006, 2008) pointed out there are two dissociable independent components contributing to WMU, one is used to modify the relevant representations in memory, the other one is used to protect the contents of WM against interference. Some empirical studies also embraced this view (Artuso \& Palladino, 2011; RacLubashevsky \& Kessler, 2016b). For example, in the n-back task, the mismatch trials containing a switch cost was performed slower than the match trials, and the lure trials (no-longer/no-yet relevant item corresponds to the currently presented item) were performed slower than the mismatch trials due to more similarity-based interference they caused (Szmalec et al., 2011). The memory of previous trials affected the current performance (Rac-Lubashevsky \& Kessler, 2016b; Szmalec, Demanet, Vandierendonck, \& Verbruggen, 2009). How does the control process work? occurs. The other one is proactive control, which is anticipatory goal-driven. It is responsible for early selection by anticipating and preventing interference before it occurs (Braver, 2012; Braver et al., 2012). Which cognitive control is the crucial contributor to WMU aging? Some evidence 
93 showed that age selectively impaired cognitive control. Recent studies reported that old adults

94 had selective difficulty in memorizing content-context associations but not in isolated contents

95 (Artuso, Cavallini, Bottiroli, \& Palladino, 2017; Artuso \& Palladino, 2011; McCormick-Huhn,

96 Chen, Wyble, \& Dennis, 2018; Old \& Naveh-Benjamin, 2008; Pelegrina, Borella, Carretti, \&

97 Lechuga, 2012) and the delays in selection were longer with a function of memory load (Artuso

et al., 2017), implying that proactive control was impaired with aging. But Xiang et al. (2016)

reported that older adults had selective deficits in reactive control.

Previous literature comparing young with old adults found an aging effect on WMU,

however, the progression of age-related changes and the crucial element causing WMU aging

were unknown because of the exclusion of middle-age adults in the previous studies. Previous

studies suggested that besides vocabulary knowledge, which increases with aging (Miller \&

Lachman, 2003; Salthouse, 2010; Singh-Manoux et al., 2012), most cognitive functions decline

with aging and present variant recession cycles. For example, content-context binding (Cowan,

Naveh-Benjamin, Kilb, \& Saults, 2006; Hommel, Kray, \& Lindenberger, 2011; Siegel, 1994;

Swanson, 2017) and switch (Kray, Eber, \& Lindenberger, 2004; Reimers \& Maylor, 2005)

decrease approximately linearly across the adult life-span. The decline of memory, process speed,

inhibition and reasoning begin from middle age (Anstey, Sargent-Cox, Eramudugolla, Magliano,

\& Shaw, 2015; Borella et al., 2008; Davis et al., 2017; M. L. Hughes, Agrigoroaei, Jeon,

Bruzzese, \& Lachman, 2018; Persad, Abeles, Zacks, \& Denburg, 2002; Singh-Manoux et al., 
This study focused on verifying whether inefficient interference control is a crucial

115

116

117

118

119

120

121

122

123

124

125

126

127

128

129

130

131

132

133

134

135

contributor to WMU aging across the adult life span and employed 1-back test, which includes

two stimuli. The interference difficulty was manipulated by adjusting the sequence relationship.

Sequential interference had an accumulative effect in N-back test (Oberauer, Souza, Druey, \&

Gade, 2013; Salmi et al., 2018; Soetens, Boer, \& Hueting, 1985) and only lure trial N-1 showed

a significant sequence effect in 1-back test (Rac-Lubashevsky \& Kessler, 2016b), which had been proved by previous studies. Four sequence patterns were distinguished by the sequence of 3

trials in a row. The main objective is to assess age-changes of WMU in four sequence patterns. If

WMU aging is attributed to inefficient interferent control, the age-related decline was steeper as interference increases. The hypotheses stated that 1) WMU performance will decline with interference increase, 2) the WMU degradation begins from middle-age and becomes steeper in old age, and 3) age-related decline is getting steeper as interference increases.

\section{Methods and materials}

\section{Ethical approval}

This study received approval from the Ethics Committee of Shanghai University of Sport (No. 2017044).

\section{Participants}

The sample consisted of 112 adult participants, 28 older adults (21 female) ranging from 60-78 years of age $(M=67.68, S D=4.23) ; 28$ middle-age adults (25 female) ranging from $45-59$ years of age $(M=54.25, S D=4.84) ; 28$ adults (11 female) ranging from $26-44$ years of age $(M=31.68$, $S D=4.63)$; and 28 young adults (26 female) ranging from $18-25$ years of age $(M=22.71$, $S D=1.67)$, recruited through Shanghai University of Sport and local communities. Participants 
136

137

138

139

140

141

142

143

144

145

146

147

148

149

150

151

152

153

154

155

156

157

were compensated for a small gift for their participation. All participants didn't have cognitive impairment as tested by the Mini-mental State Examination and signed the informed consent (see Table 1).

(Insert table 1 about here)

\section{Stimuli}

The 1-back task was adopted from Rac-Lubashevsky and Kessler (2016a, 2016b) to observe a participant's ability to update information. This task involved the continuous presentation of a solid gray square " $\square$ " (side length $38 \mathrm{~mm}$ ) or a solid gray circle " $\bigcirc$ " (the diameter of $38 \mathrm{~mm}$ ).

A Lenovo computer with a 17-inch VGA display (frequency $60 \mathrm{~Hz}$, resolution $1366 \times 768$ ) was used for stimulus presentation, and the Matlab2015 software package (Psychtoolbox 3.0) was used for response sampling. All stimuli were presented on a white background.

\section{Task}

Participants were instructed to monitor stimuli subtended a visual angle of $5.73^{\circ}$ horizontally and $5.73^{\circ}$ vertically from viewing distance $55 \mathrm{~cm}$ and decided whether the presented shape was the same as the one that had been presented immediately before by pressing one of two keys on a response box: "3" for "yes" and "1" for "no". The test consisted of a practice block and two formal experimental blocks. The practice block contained 20 trials with feedback to familiarize the participant with the task. The system automatically transitions to the formal experimental session until the accuracy reached up to $66.7 \%$ in the practice session, otherwise, the system remained in the practice session. The data of the practice session was not recorded.

Each block of the formal test included 42 trials and started with a blank fixation screen presented for $500 \mathrm{~ms}$, the stimulus " $\square$ " or " $\bigcirc$ " was then presented for $500 \mathrm{~ms}$ randomly, followed by a white display for $1500 \mathrm{~ms}$. Participants were required to respond quickly and accurately as soon as the target stimuli appeared. The maximum duration for a response to be made was $2000 \mathrm{~ms}$ (the presentation of the stimulus $500 \mathrm{~ms}+$ the presentation of white display $1500 \mathrm{~ms})$. Reaction time and accuracy were automatically recorded by Matlab2015. If the 
162 participant didn't respond in time $(\mathrm{RT}>2000 \mathrm{~ms})$, the reaction time was recorded as an error.

163 Participants were assured with adequate rest between 2 blocks of the experiment (Fig. 1).

$164 \quad$ (Insert Figure 1 about here)

165 Statistical Analysis

166 Previous studies reported that only the lure trial (trial N-1) influenced the current performance 167 (Trial N+1) in the 1-back task (Rac-Lubashevsky \& Kessler, 2016b, 2016a; Soetens et al., 1985; 168 Szmalec et al., 2011). Accordingly, the data were classified by the sequence of 3 trials in a row, and 4 sequence patterns could be identified: 1) Repeating the same stimulus three times (named as RR; including $\square \square \square$ and $\bigcirc \bigcirc \bigcirc$ ); 2) Repeating the same stimulus twice followed by a different stimulus, (named as RA; including $\bigcirc \bigcirc \square$ and $\square \square \bigcirc$ ); 3) Altering the stimulus in the and $\square \bigcirc \bigcirc$ ); 4) Altering the stimuli twice in the 3 trials (named as AA; including $\square \square$ and $\square \bigcirc \square$ ) (Fig. 2).

\section{(Insert Figure 2 about here)}

RT data were cleaned by removing inaccurate and no response trials. RT below $100 \mathrm{~ms}$ was treated as response error, and outlying trials which were more than 3 standard deviations above each sequence patter condition mean were removed. Time cost and accuracy are known to be negatively related (Pachella, 1974). Particularly, with increasing difficulty, participants may decide to emphasize either speed or accuracy. Disregard accuracy or analyzing the accuracy and RTs separately impair the power to detect relationships and interactions (Hughes, Linck, Bowles, Koeth, \& Bunting, 2014). Consequently, inverse efficiency score (IES), RT with consideration of response accuracy, has been proposed as a good way (Bruyer \& Brysbaert, 2011; Townsend \& Ashby, 1978) and be used to evaluate updating in this study. IES is calculated as RT divided by PC (the proportion of correct responses). The formula is IES $=\mathrm{RT} / \mathrm{PC}$. Performance and IES are negatively related, a lower IES corresponds to better performance. A $4 \times 4$ (Sequence 
187

188

189

190

191

192

pattern $\times$ Age) mixed-design ANOVA with sequence pattern $(\mathrm{RR}, \mathrm{RA}, \mathrm{AR}, \mathrm{AA})$ as withinsubjects factor and Age (18-25 age, 26-44 age, 45-59 age, $\geq 60$ age) as a between-subjects factor was employed to examine the effects of interference and age on WMU.

\section{Results}

The 2-way ANOVA showed significant main effects for Age $\left[F(3,108)=17.43, p<0.001, \eta_{p}^{2}\right.$ $=0.326]$, Pattern $\left[F(3,108)=132.27, p<0.001, \eta_{p}^{2}=0.551\right]$. Tukey post-hoc comparisons showed that young adults outperformed middle-age $(p<0.001)$ and old $(p<0.001)$, the same results appeared between adults and middle-age $(p<0.01)$ and old $(p<0.001)$; the difference were not observed both between young adults and adults group $(\mathrm{p}=0.725)$ and middle-age and old group $(\mathrm{p}=0.554)$. That implied the serious degradation of WMU began in middle-age. The significant differences among the 4 sequence patterns were also observed, implying the declined performance with increasing interference, IES of RR was the lowest, then RA, and then AR, AA was the highest $(p<0.001)$.

The interaction between Age and Pattern $\left[F(3,324)=6.55, p<0.001, \eta_{p}^{2}=0.121\right]$ reached significance. The simple main effect analysis showed a significant age effect in $\operatorname{RA}[F(3,432)=$ 3.87, $p<0.01]$ and AA $[F(3,432)=35.79, p<0.001]$, the post hoc Tukey's HSD test showed that both young groups outperformed the old group in RA, and they outperformed both middleage and old groups in AA (see Table 2). In summary, WMU declined with increasing age, however, the selective age-related impaired was presented (see Fig 3).

(Insert table 2 about here)

(Insert Figure 3 about here)

\section{Discussion}

The study aimed to analyze the impact of age on WMU interference control by a cross-sectional comparison. Updating requires holding temporary binding between contents and contexts and unbinding outdated contents in time because WM capacity is limited. Cognitive control should 
212 hold maximal flexibility to find an optimal balance between maintaining and replacing to ensure 213 performance, especially on a strong interference task. In this study, the interference difficulty 214 was manipulated by adjusting the sequence relationship, four sequence patterns including RR, 215 RA, AR, AA patterns were classified by 3 trials in a row. The participants were divided into the 216 youngster, middle-aged and the elderly. Besides, the young participants were subdivided into 217 young adults and adults, because middle-aged had been understudied in previous aging studies, 218 potentially due to that the difference between middle age and other groups was not observed 219 (Phillips et al., 2011). Subdivision of youth groups could help us to acquire a better understanding of the progression of age-related changes across adult life-span particularly from young to middle age. Our results showed two young groups outperformed the old group in both 222 RA and AA and they were additionally better than the middle-age group in AA sequential 223 pattern.

Four sequential patterns were classified by 3 trials in a row. As we expected, the performance declined with interference increase. Rac-Lubashevsky and Kessler （2016a, 2016b) separated several contributions to updating by reference-back task. The reference-back task contains reference trials, which is presented inside a red frame, and comparison trials, which is presented inside a blue frame. The participants are required to judge whether the presented stimulus is the same as, or different from, the previous reference trials. In other words, the comparison trials should be compared to the previous reference trails, but should not be updated. Compared with comparison trials, reference trials contain an additional updating cost. In this study, repetition trials as comparison trials should not be updated, the cost was smaller than alternation trials ( $\mathrm{RR}<\mathrm{RA}$; $\mathrm{AR}<\mathrm{AA})$. The previous study of 2-alternative forced-choice task or 1-back choice task found AR elicited a stimulus-response (S-R) conflict response which contains additional time cost and accurate cost than other patterns (Rac-Lubashevsky \& Kessler, 2016b; Szmalec et al., 2009). But the response of 1-back depended on the relationship between the previous trial and the current stimulus. AA requires the participant to switch focus to relevant information and to prevent similarly interference in terms of ensuring a currently appropriate 
239

240

241

242

243

244

245

246

247

248

249

250

251

252

253

254

255

256

257

258

259

260

261

262

263

264

265

action (Wylie \& Allport, 2000). In this study, an accumulative effect of the sequence interference was observed, especially in AA (RR $<$ AR; RA $<$ AA), suggesting two independent sources of contribution to updating. That was consistent with previous studies (Artuso \& Palladino, 2011; Kessler \& Meiran, 2006, 2008; Rac-Lubashevsky \& Kessler, 2016b).

A better WMU of young adults over older adults was proved in this study as well as in many previous studies (Artuso et al., 2017; Guerreiro, Murphy, \& Van Gerven, 2013; Hommel et al., 2011; Pelegrina et al., 2012; Phillips et al., 2011; Schmiedek et al., 2009). And the superior performance of young groups to the middle age group was observed in this study. No difference was found between young adult and adult. No difference was found between middle-aged and old adults on total mean IES. Only two stimuli were employed in this study to induce larger similarity-based interference, used IES to increase the detection power, and shortened ISI to prevent participators from refreshing during free time. Even under the circumstances, the difference between young and middle age was observed only in the pattern with the biggest interference (AA). The task of previous studies was possibly too easy to observe the early onset of cognitive impairment at middle age. This is possibly the reason why middle-aged understudied in previous aging studies.

Age-related changes varied among 4 sequential patterns and only appeared in RA and AA. The difference between young and old adults was observed in RA and AA. RA and AA contain a characteristic that requires updating the new item and replacing the outdated one after the onset of new items. The age-related decline was observed in alternation trials disregarding prior sequence characteristics, suggesting that age only affected just-in-time selection. The reactive control, but not proactive control, declined with aging (Xiang et al., 2016). That challenged earlier views of age can only affect proactive control (Botvinick, Carter, Braver, Barch, \& Cohen, 2001; Braver \& West, 2015). The difference between young and middle-aged was observed in AA, but not in RA. Compared with RA, AA elicits more similarity-based interference and requires more cognitive control than RA. The difference between young and middle-aged was gradually revealed with the increase of interference, while the difference between young and old 
266

267

268

269

270

271

272

273

274

275

276

277

278

279

280

281

282

283

284

285

286

287

288

289

290

291

292

remained to be apparent, reflecting the degradation of WMU begins from the middle-age. The age-related decline only appeared in mismatch trials, implying age-related switch deficit might be a crucial contributor to WMU aging across the adult lifespan. However, previous switch aging studies suggested that special switch cost, which represented the differences between switch and nonswitch trials within a block as in this study, were largely unrelated to age; only the global switch, the ability to efficiently coordinate multiple tasks, was negatively affected by age (Kray \& Lindenberger, 2000; Mayr \& Liebscher, 2001). Using varied tasks may cause different results. The N-back task may be a measure of cognitive control when it involves higher interference (Szmalec et al., 2011). And its interference can continuously increase by manipulating the sequence relationship. The task-induced huge similarity-based interference due to employing only 2 stimuli in this study and the IES index was adopted to ensure the power. All of this may prompt some new findings. Age-related decline in reactive interference control but not in proactive control was gradually revealed after middle age and the decline got steeper with age. In the future, research, particularly including middle age, should consider the impact of task difficulty and the power of indexing on the result. And future studies should explore further the relationship between updating, interference, and aging using the N-back task.

\section{Limitations}

The present study had a few limitations. Firstly, the main motivation of the study is to explore the progression of WMU aging by including the middle age group, but the sample size of the cross-sectional design was too small to further explore timing detail of onset of aging and the progression of aging after 60 age. Secondly, the cross-sectional design could not avoid individual differences within age groups. A larger sample of participants should be recruited in future studies and combine with cross-sectional and longitudinal follow-up design, which may offset the defect of the present study. Finally, the lack of information on education and other socioeconomic variables of the studied population may limit the generalization of the findings.

\section{Conclusions}

In conclusion, with the increase of difficulty in the task, the difference in reactive cognitive 
293

294

295

296

297

298

299

300

301

302

303

304

305

306

307

308

309

310

311

312

313

314

315

316

317

318

319

320

321

322

323

324

325

326

327

328

329

control between young and middle age was gradually revealed, while the difference between young and old remained to be apparent. The results reflected that WMU degradation may begin from the middle age and become steeper in old age. WMU aging presents selective impairment.

Only reactive interference control, but not proactive interference control, shows pronounced agerelated decline, which mainly reflects a larger special switch cost. Age-related switch decline may be a crucial contributor to WMU in aging. The preliminary results can inform future studies to further explore the whole lifespan trajectories of cognitive functions.

\section{References}

Anderson, N. D., \& Craik, F. I. M. (2017). 50 Years of Cognitive Aging Theory. Journals of Gerontology - Series B Psychological Sciences and Social Sciences, 72(1), 1-6. https://doi.org/10.1093/geronb/gbw108

Anstey, K. J., Sargent-Cox, K., Eramudugolla, R., Magliano, D. J., \& Shaw, J. E. (2015). Association of cognitive function with glucose tolerance and trajectories of glucose tolerance over 12 years in the AusDiab study. Alzheimer's Research and Therapy, 7(1), 48. https://doi.org/10.1186/s13195-015-0131-4

Arjona, A., Escudero, M., \& Gómez, C. M. (2016). Cue validity probability influences neural processing of targets. Biological Psychology, 119, 171-183. https://doi.org/10.1016/j.biopsycho.2016.07.001

Artuso, C., Cavallini, E., Bottiroli, S., \& Palladino, P. (2017). Updating working memory: memory load matters with aging. Aging Clinical and Experimental Research, 29(3), 371377. https://doi.org/10.1007/s40520-016-0581-y

Artuso, C., \& Palladino, P. (2011). Content-context binding in verbal working memory updating: On-line and off-line effects. Acta Psychologica, 136(3), 363-369. https://doi.org/10.1016/j.actpsy.2011.01.001

Artuso, C., \& Palladino, P. (2018). How sublexical association strength modulates updating: Cognitive and strategic effects. Memory and Cognition, 46(2), 285-297. https://doi.org/10.3758/s13421-017-0764-6

Borella, E., Carretti, B., Cornoldi, C., \& De Beni, R. (2007). Working memory, control of interference and everyday experience of thought interference: When age makes the difference. Aging Clinical and Experimental Research, 19(3), 200-206. https://doi.org/10.1007/BF03324690

Borella, E., Carretti, B., \& De Beni, R. (2008). Working memory and inhibition across the adult life-span. Acta Psychologica, 128(1), 33-44. https://doi.org/10.1016/j.actpsy.2007.09.008

Botvinick, M. M., Carter, C. S., Braver, T. S., Barch, D. M., \& Cohen, J. D. (2001). Conflict monitoring and cognitive control. Psychological Review, 108(3), 624-652. https://doi.org/10.1037/0033-295X.108.3.624 
330

331

332

333

334

335

336

337

338

339

340

341

342

343

344

345

346

347

348

349

350

351

352

353

354

355

356

357

358

359

360

361

362

363

364

365

366

367

368

369

370

Braver, T. S. (2012). The variable nature of cognitive control: A dual mechanisms framework. Trends in Cognitive Sciences, 16(2), 106-113. https://doi.org/10.1016/j.tics.2011.12.010

Braver, T. S., Gray, J. R., \& Burgess, G. C. (2012). Explaining the Many Varieties of Working Memory Variation: Dual Mechanisms of Cognitive Control. In C. A. Conway, M. K. Jarrold, A. Miyake, \& J. Towse (Eds.), Variation in Working Memory (pp. 76-106). Oxford: Oxford University Press. https://doi.org/10.1093/acprof:oso/9780195168648.003.0004

Braver, T. S., \& West, R. (2015). Working Memory, Executive Control, and Aging. In F. I. M. Craik \& T. A. Salthouse (Eds.), The Handbook of Aging and Cognition (pp. 311-372). New York and Hove. https://doi.org/10.4324/9780203837665.ch7

Bruce, M. L., Hoff, R. A., Jacobs, S. C., \& Leaf, P. J. (1995). The effects of cognitive impairment on 9-year mortality in a community sample. Journals of Gerontology - Series B Psychological Sciences and Social Sciences, 50 B(6), P289-P296. https://doi.org/10.1093/geronb/50B.6.P289

Bruyer, R., \& Brysbaert, M. (2011). Combining Speed and Accuracy in Cognitive Psychology: Is the Inverse Efficiency Score (IES) a Better Dependent Variable than the Mean Reaction Time (RT) and the Percentage Of Errors (PE)? Psychologica Belgica, 51(1), 5. https://doi.org/10.5334/pb-51-1-5

Cowan, N., Naveh-Benjamin, M., Kilb, A., \& Saults, J. S. (2006). Life-span development of visual working memory: When is feature binding difficult? Developmental Psychology, 42(6), 1089-1102. https://doi.org/10.1037/0012-1649.42.6.1089

Dagry, I., Vergauwe, E., \& Barrouillet, P. (2017). Cleaning working memory: The fate of distractors. Journal of Memory and Language, 92, 327-342. https://doi.org/10.1016/j.jml.2016.08.002

Davis, D., Bendayan, R., Muniz Terrera, G., Hardy, R., Richards, M., \& Kuh, D. (2017). Decline in Search Speed and Verbal Memory over 26 Years of Midlife in a British Birth Cohort. Neuroepidemiology, 49(3-4), 121-128. https://doi.org/10.1159/000481136

De Beni, R., \& Palladino, P. (2004). Decline in working memory updating through ageing: Intrusion error analyses. Memory, 12(1), 75-89. https://doi.org/10.1080/09658210244000568

Fiore, F., Borella, E., Mammarella, I. C., \& Cornoldi, C. (2011). Mental imagery in a visuospatial working memory task and modulation of activation. Journal of Cognitive Psychology, 23(1), 52-59. https://doi.org/10.1080/20445911.2011.454497

Guerreiro, M. J. S., Murphy, D. R., \& Van Gerven, P. W. M. (2013). Making sense of agerelated distractibility: The critical role of sensory modality. Acta Psychologica, 142(2), 184-194. https://doi.org/10.1016/j.actpsy.2012.11.007

Hommel, B., Kray, J., \& Lindenberger, U. (2011). Feature integration across the lifespan: Stickier stimulus-response bindings in children and older adults. Frontiers in Psychology, 2, 268. https://doi.org/10.3389/fpsyg.2011.00268

Hughes, M. L., Agrigoroaei, S., Jeon, M., Bruzzese, M., \& Lachman, M. E. (2018). Change in Cognitive Performance from Midlife into Old Age: Findings from the Midlife in the United States (MIDUS) Study. Journal of the International Neuropsychological Society, 24(8), 
805-820. https://doi.org/10.1017/S1355617718000425

Hughes, M. M., Linck, J. A., Bowles, A. R., Koeth, J. T., \& Bunting, M. F. (2014). Alternatives to switch-cost scoring in the task-switching paradigm: Their reliability and increased validity. Behavior Research Methods, 46(3), 702-721. https://doi.org/10.3758/s13428-0130411-5

Kato, K., Nakamura, A., Kato, T., Kuratsubo, I., Iwata, K., Yamagishi, M., \& Ito, K. (2016). Age-Related Changes in Attentional Control Using an N-Back Working Memory Paradigm. Experimental Aging Research, 42(4), 390-402. https://doi.org/10.1080/0361073x.2016.1191867

Kessler, Y., \& Meiran, N. (2006). All updateable objects in working memory are updated whenever any of them are modified: Evidence from the memory updating paradigm. Journal of Experimental Psychology: Learning Memory and Cognition, 32(3), 570-585. https://doi.org/10.1037/0278-7393.32.3.570

Kessler, Y., \& Meiran, N. (2008). Two Dissociable Updating Processes in Working Memory. Journal of Experimental Psychology: Learning Memory and Cognition, 34(6), 1339-1348. https://doi.org/10.1037/a0013078

Kray, J., Eber, J., \& Lindenberger, U. (2004). Age differences in executive functioning across the lifespan: The role of verbalization in task preparation. Acta Psychologica, 115(2-3), 143-165. https://doi.org/10.1016/j.actpsy.2003.12.001

Kray, J., \& Lindenberger, U. (2000). Adult age differences in task switching. Psychology and Aging, 15(1), 126-147. https://doi.org/10.1037/0882-7974.15.1.126

Mayr, U., \& Liebscher, T. (2001). Is there an age deficit in the selection of mental sets? European Journal of Cognitive Psychology. https://doi.org/10.1080/09541440042000214

McCormick-Huhn, J. M., Chen, H., Wyble, B. P., \& Dennis, N. A. (2018). Using attribute amnesia to test the limits of hyper-binding and associative deficits in working memory. Psychology and Aging, 33(1), 165-175. https://doi.org/10.1037/pag0000213

Miller, L. M. S., \& Lachman, M. E. (2003). Cognitive Performance and the Role of Control Beliefs in Midlife. Aging, Neuropsychology, and Cognition, 7(2), 69-85. https://doi.org/10.1076/1382-5585(200006)7:2;1-u;ft069

Morris, N., \& Jones, D. M. (1990). Memory updating in working memory. The Role of the Central Executive, 81(2), 111-121. https://doi.org/10.1111/j.2044-8295.1990.tb02349.x

Oberauer, K. (2009). Design for a Working Memory. Psychology of Learning and Motivation, 57(09), 45-100. https://doi.org/10.1016/B978-0-12-394293-7.00002-9

Oberauer, K., Souza, A. S., Druey, M. D., \& Gade, M. (2013). Analogous mechanisms of selection and updating in declarative and procedural working memory: Experiments and a computational model. Cognitive Psychology, 66(2), 157-211. https://doi.org/10.1016/j.cogpsych.2012.11.001

Old, S. R., \& Naveh-Benjamin, M. (2008). Differential Effects of Age on Item and Associative Measures of Memory: A Meta-Analysis. Psychology and Aging, 23(1), 104-118. https://doi.org/10.1037/0882-7974.23.1.104

Pachella, R. G. (1974). The interpretation of reaction time in information processing research. 
412

413

414

415

416

417

418

419

420

421

422

423

424

425

426

427

428

429

430

431

432

433

434

435

436

437

438

439

440

441

442

443

444

445

446

447

448

449

450

451

452
Human Information Processing: Tutorials in Performance and Cognition, (November), 4182.

Pelegrina, S., Borella, E., Carretti, B., \& Lechuga, M. T. (2012). Similarity-based interference in a working memory numerical updating task: Age-related differences between younger and older adults. Experimental Psychology, 59(4), 183-189. https://doi.org/10.1027/16183169/a000142

Persad, C. C., Abeles, N., Zacks, R. T., \& Denburg, N. L. (2002). Inhibitory changes after age 60 and their relationship to measures of attention and memory. Journals of Gerontology Series B Psychological Sciences and Social Sciences, 57(3), P223-P232. https://doi.org/10.1093/geronb/57.3.P223

Phillips, L. H., Bull, R., Allen, R., Insch, P., Burr, K., \& Ogg, W. (2011). Lifespan aging and belief reasoning: Influences of executive function and social cue decoding. Cognition, 120(2), 236-247. https://doi.org/10.1016/j.cognition.2011.05.003

Podell, J. E., Sambataro, F., Murty, V. P., Emery, M. R., Tong, Y., Das, S., ... Mattay, V. S. (2012). Neurophysiological correlates of age-related changes in working memory updating. NeuroImage, 62(3), 2151-2160. https://doi.org/10.1016/j.neuroimage.2012.05.066

Rac-Lubashevsky, R., \& Kessler, Y. (2016a). Decomposing the n-back task: An individual differences study using the reference-back paradigm. Neuropsychologia, 90, 190-199. https://doi.org/10.1016/j.neuropsychologia.2016.07.013

Rac-Lubashevsky, R., \& Kessler, Y. (2016b). Dissociating working memory updating and automatic updating: The reference-back paradigm. Journal of Experimental Psychology: Learning Memory and Cognition, 42(6), 951-969. https://doi.org/10.1037/xlm0000219

Reimers, S., \& Maylor, E. A. (2005). Task switching across the life Span: Effects of age on general and specific switch costs. Developmental Psychology, 41(4), 661-671. https://doi.org/10.1037/0012-1649.41.4.661

Royall, D. R., Palmer, R., Chiodo, L. K., \& Polk, M. J. (2005). Normal rates of cognitive change in successful aging: The freedom house study. Journal of the International Neuropsychological Society, 11(7), 899-909. https://doi.org/10.1017/S135561770505109X

Salmi, J., Soveri, A., Rodríguez-Fornells, A., Laine, M., Lehtonen, M., \& Vilà-Balló, A. (2018). Neural signatures for active maintenance and interference during working memory updating. Biological Psychology, 132, 233-243. https://doi.org/10.1016/j.biopsycho.2018.01.007

Salthouse, T. A. (2010). Selective review of cognitive aging. Journal of the International Neuropsychological Society, 16(5), 754-760. https://doi.org/10.1017/S1355617710000706

Sambataro, F., Podell, J. E., Murty, V. P., Das, S., Kolachana, B., Goldberg, T. E., ... Mattay, V. S. (2015). A variable number of tandem repeats in the $3^{\prime}$-untranslated region of the dopamine transporter modulates striatal function during working memory updating across the adult age span. European Journal of Neuroscience, 42(3), 1912-1918. https://doi.org/10.1111/ejn.12956

Schmiedek, F., Li, S. C., \& Lindenberger, U. (2009). Interference and Facilitation in Spatial Working Memory: Age-Associated Differences in Lure Effects in the N-Back Paradigm. Psychology and Aging, 24(1), 203-210. https://doi.org/10.1037/a0014685 
453

454

455

456

457

458

459

460

461

462

463

464

465

466

467

468

469

470

471

472

473

474

475

476

477

478

479

480

481

482

483

484

485

486
Siegel, L. S. (1994). Working Memory and Reading: A Life-span Perspective. International Journal of Behavioral Development, 17(1), 109-124. https://doi.org/10.1177/016502549401700107

Singh-Manoux, A., Kivimaki, M., Glymour, M. M., Elbaz, A., Berr, C., Ebmeier, K. P., ... Dugravot, A. (2012). Timing of onset of cognitive decline: Results from Whitehall II prospective cohort study. BMJ (Online), 344(7840). https://doi.org/10.1136/bmj.d7622 Soetens, E., Boer, L. C., \& Hueting, J. E. (1985). Expectancy or Automatic Facilitation? Separating Sequential Effects in Two-Choice Reaction Time. Journal of Experimental Psychology: Human Perception and Performance, 11(5), 598-616. https://doi.org/10.1037/0096-1523.11.5.598

Swanson, H. L. (2017). Verbal and visual-spatial working memory: What develops over a life Span? Developmental Psychology, 53(5), 971-995. https://doi.org/10.1037/dev0000291

Szmalec, A., Demanet, J., Vandierendonck, A., \& Verbruggen, F. (2009). Investigating the role of conflict resolution in memory updating by means of the one-back choice RT task. Psychological Research, 73(3), 390-406. https://doi.org/10.1007/s00426-008-0149-3

Szmalec, A., Verbruggen, F., Vandierendonck, A., \& Kemps, E. (2011). Control of Interference During Working Memory Updating. Journal of Experimental Psychology: Human Perception and Performance, 37(1), 137-151. https://doi.org/10.1037/a0020365

Townsend, J. T., \& Ashby, F. G. (1978). Methods of modeling capacity in simple processing systems. In I. J. Castellan \& F. Restle (Eds.), Cognitive theory (Vol. 3) (pp. 200-239). Hillsdale, NJ: Erlbaum. https://doi.org/10.1163/q3_SIM_00374

Verhaeghen, P., \& Basak, C. (2005). Ageing and switching of the focus of attention in working memory: Results from a modified N-Back task. Quarterly Journal of Experimental Psychology Section A: Human Experimental Psychology, 58(1), 134-154. https://doi.org/10.1080/02724980443000241

Wylie, G., \& Allport, A. (2000). Task switching and the measurement of "switch costs." Psychological Research, 63(3-4), 212-233. https://doi.org/10.1007/s004269900003

Xiang, L., Zhang, B., Wang, B., Jiang, J., Zhang, F., \& Hu, Z. (2016). The Effect of Aging on the Dynamics of Reactive and Proactive Cognitive Control of Response Interference. Frontiers in Psychology, 7, 1-10. https://doi.org/10.3389/fpsyg.2016.01640

Zimprich, D., \& Mascherek, A. (2010). Five views of a secret: Does cognition change during middle adulthood? European Journal of Ageing, 7(3), 135-146. https://doi.org/10.1007/s10433-010-0161-5 
Table $\mathbf{1}$ (on next page)

Participant demographics 
1 Table1:

2 Participant demographics

\begin{tabular}{cccccc}
\hline Age group & N & Mean age & BMI & Females & MMSE score \\
\hline Yong-adults & 28 & $22.71(1.67)$ & $20.4(1.8)$ & 26 & - \\
Adults & 28 & $31.68(4.63)$ & $22.8(2.8)$ & 11 & -- \\
Middle-aged adults & 28 & $54.21(4.06)$ & $23(2.7)$ & 25 & -- \\
Old & 28 & $67.68(4.37)$ & $23(2.2)$ & 21 & $27.8(2.2)$ \\
\hline
\end{tabular}

3 Note. SD in brackets. MMSE = Mini-Mental State Examination. 


\section{Table 2 (on next page)}

Age group comparison between Young-young (Y-y), Old-young (O-y), Middle-age (M-a), Old age (O-a) about four sequential patterns.

Inverse efficiency score calculating as RT divided by PC (the proportion of correct responses) was evaluated on the performance in 4 patterns. 
1 Table 2:

2 Age group comparison between Young adult (18-25 age), adult (26-44 age), Middle-age (45-59

3 age), Old age (60- age) about four sequential patterns.

4 Inverse efficiency score calculating as RT divided by PC (the proportion of correct responses)

5 was evaluated on the performance in 4 patterns.

\begin{tabular}{|c|c|c|c|c|c|c|}
\hline \multirow{2}{*}{$\begin{array}{l}\text { Sequential } \\
\text { Pattern }\end{array}$} & \multicolumn{4}{|c|}{ Age Groups (ms) } & \multirow{2}{*}{$\begin{array}{l}\text { simple main } \\
\text { effect of Age } \\
\text { (F) }\end{array}$} & \multirow{2}{*}{$\begin{array}{c}\text { post hoc Tukey HSD } \\
\text { test }\end{array}$} \\
\hline & $\begin{array}{c}18-25 \\
1\end{array}$ & $\begin{array}{c}26-44 \\
(2)\end{array}$ & $\begin{array}{c}45-59 \\
3\end{array}$ & $\begin{array}{l}60- \\
4\end{array}$ & & \\
\hline RR & $\begin{array}{l}538.2 \\
(24.2)\end{array}$ & $\begin{array}{l}608.9 \\
(37.4)\end{array}$ & $\begin{array}{c}685 \\
(37.3)\end{array}$ & $\begin{array}{l}843.2 \\
(73.2)\end{array}$ & 1.5 & \\
\hline RA & $\begin{array}{l}686.2 \\
(30.1)\end{array}$ & $\begin{array}{l}716.7 \\
(46.4)\end{array}$ & $\begin{array}{l}1004.6 \\
(56.4)\end{array}$ & $\begin{array}{c}1110 \\
(64.2)\end{array}$ & $3.87 * *$ & (1) $<$ (4) * (2) $<$ (4)* \\
\hline $\mathrm{AR}$ & $\begin{array}{l}807.9 \\
(42.3)\end{array}$ & $\begin{array}{l}965.6 \\
(77.5)\end{array}$ & $\begin{array}{c}1030 \\
(48.2)\end{array}$ & $\begin{array}{l}1210.2 \\
(90.6)\end{array}$ & 2.42 & \\
\hline AA & $\begin{array}{l}1340.8 \\
(93.2)\end{array}$ & $\begin{array}{l}1406.5 \\
(106.9)\end{array}$ & $\begin{array}{l}2488.1 \\
(256.6)\end{array}$ & $\begin{array}{l}2472.7 \\
(243.8)\end{array}$ & $35.79 * *$ & 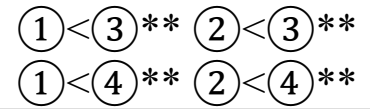 \\
\hline
\end{tabular}

$*: \mathrm{p}<0.05 ; * *: \mathrm{p}<0.01$ 


\section{Figure 1}

The 1-back task procedure

The task started with a blank fixation screen presented for $500 \mathrm{~ms}$, the stimulus " $\square$ " or " $\bigcirc$ " was then presented for $500 \mathrm{~ms}$ randomly, followed by a white display for $1500 \mathrm{~ms}$.

Participants were required to respond quickly and accurately as soon as the target stimuli appeared. If it was the same as the previous trial pressing " 1 " (same), if not pressing " 3 " (difference) The maximum duration for response to be made was $2000 \mathrm{~ms}$ (the presentation of the stimulus $500 \mathrm{~ms}+$ the presentation of white display $1500 \mathrm{~ms}$ ). 


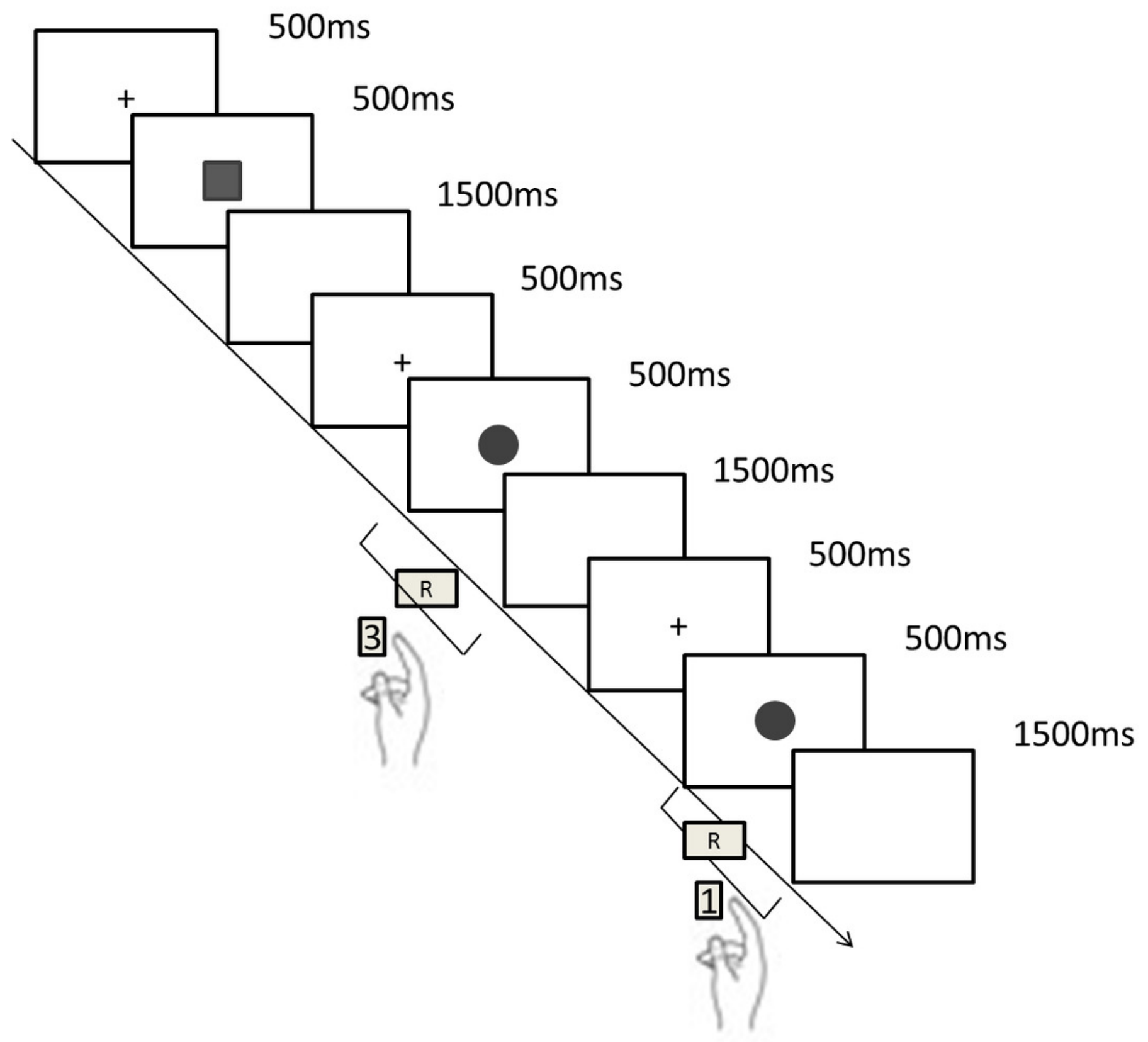


Figure 2

Four different sequential patterns with the sequence of 3 trials in a row

A: Repeating the same stimulus three times is named as RR; $B$ : Repeating the same stimulus twice followed by a different stimulus, (named as RA; including $\bigcirc \circ \square$ and $\square \square \bigcirc$ ); C: Altering the stimulus in first two followed by repeating the second stimulus on the third (named as AR; including $O \square \square$ and $\square O O$ ); D: Altering the stimuli twice in the 3 trials (named as AA ; including $\bigcirc \square \bigcirc$ and $\square \mathrm{O} \square$

A
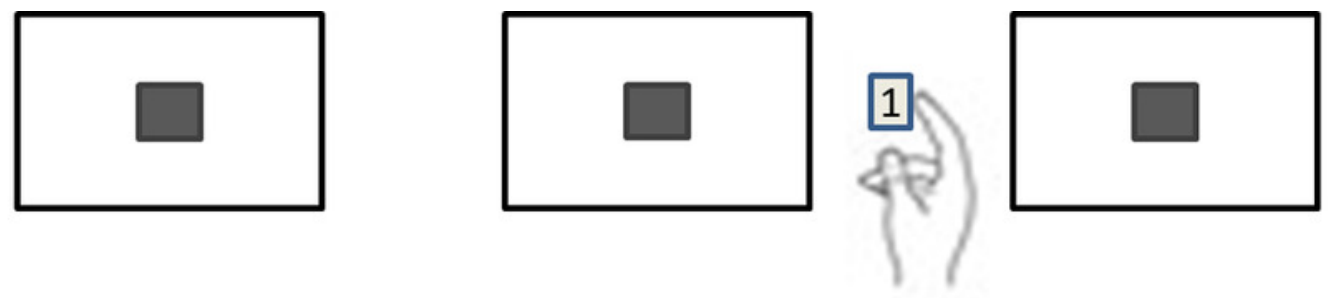

1
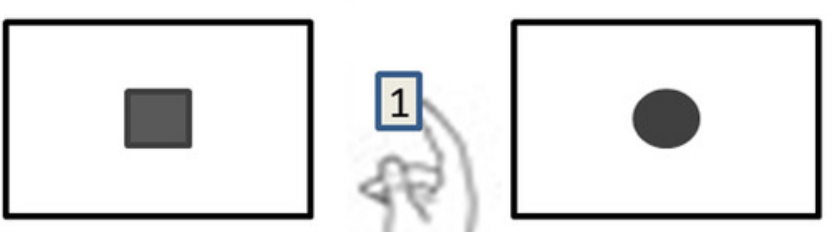

3

B
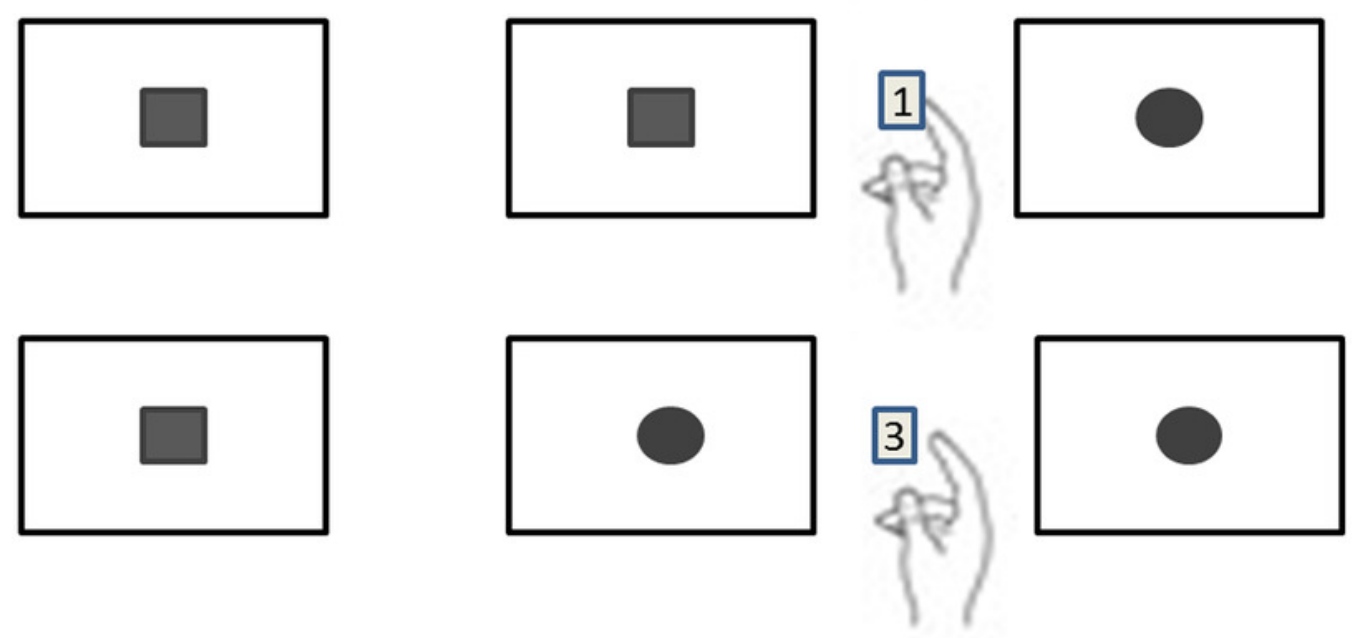

1

C
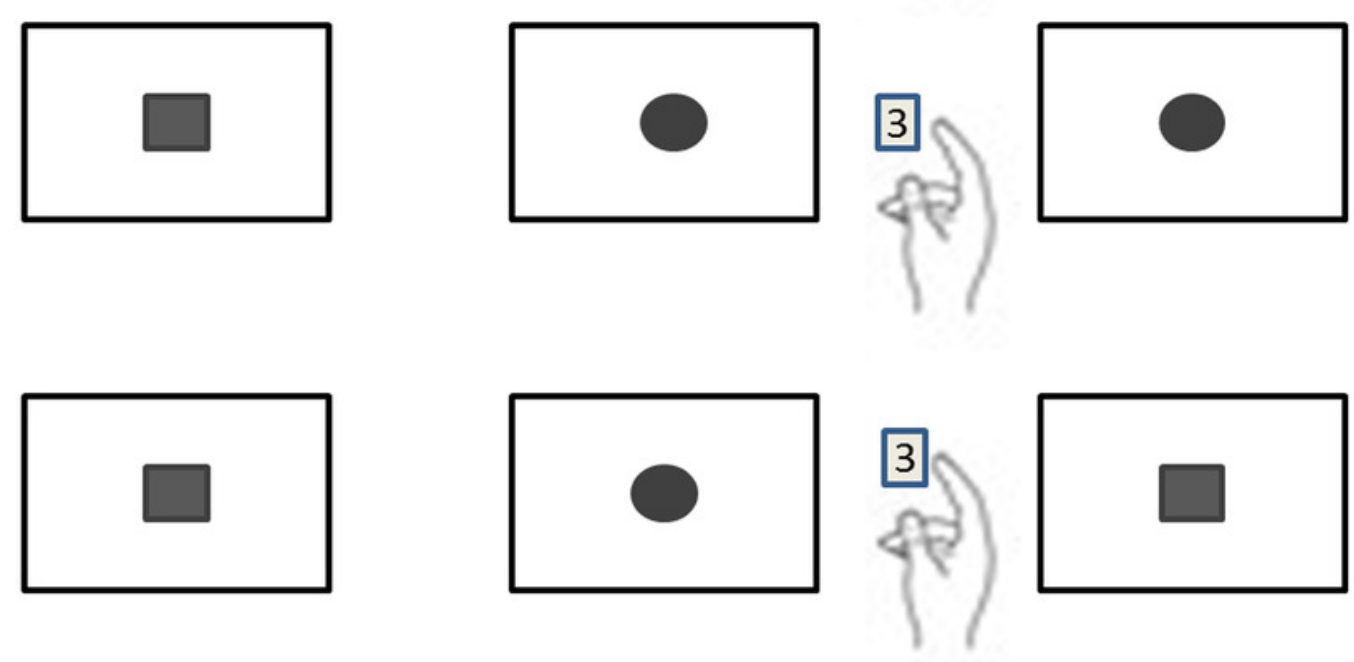

D 
Figure 3

The age-related change during various sequence patterns

$X$ axis is sequence pattern, $Y$ axis is the inverse efficiency score (RTc / PC). Error bars represent standard error.

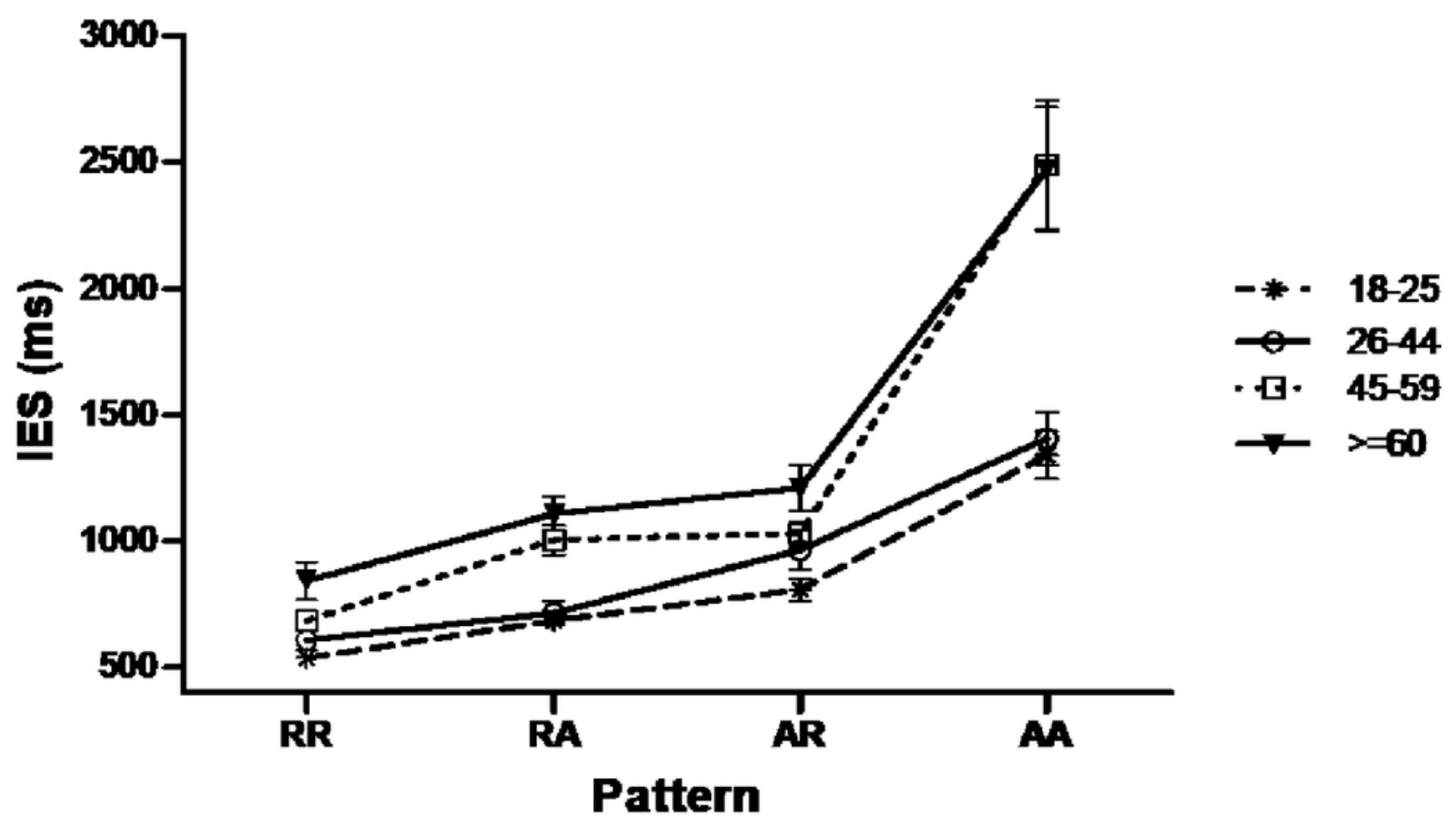

